\title{
Opsoclonus Myoclonus Ataxia Syndrome
}

\author{
Kunchapudi SK ${ }^{1}$, Kumar Praveen², Sabharwal RK ${ }^{3}$
}

\begin{abstract}
Opsoclonus myoclonus ataxia syndrome (OMAS) is a rare neurological disorder predominantly affecting young children and causing severe neurological disability. Its early identification and treatment is advocated. Here we report a two year old child presenting with abnormal movements and subsequently developed features of OMAS and responding favourably to Adrenocorticotropic hormone (ACTH).
\end{abstract}

Key words: ACTH, Neuroblastoma,OMAS, Opsoclonus.

\section{Introduction}

$\mathrm{O}$ psoclonus myoclonus ataxia (OMA) syndrome, also called 'Dancing eye syndrome', is a rare, serious and often chronic disabling neurological illness with onset in early childhood ${ }^{1}$. It was first described by Kinsbourne and often referred to as Kinsboune's syndrome. OMA is diagnosed by presence of $\geq 3$ of the following:

A. Opsoclonus (rapid, multidirectional, conjugate eye movements),

B. Myoclonus

C. Behavioural changes and/or sleep disturbances and

D. Neuroblastoma²

These findings may not be present at onset and may develop sequentially as seen in our case.

\section{The Case}

A two years age male child presented with complaints of abnormal movements of the body and inability to sit without support for past seven days. The abnormal movements were sudden shake like movements, initially started on right upper limb, and progressed to involve head and all other limbs over a period of one day. Parents noticed that these movements get aggravated on crying and activity and ceased on sleeping. They also found that child was unable to sit and stand without support and has difficulty in reaching for objects or picking them up with hands. There was history of upper respiratory tract infection three weeks ago, for which he received treatment with amoxicillin and chlorpheniramine maleate for three days. There was no history of concurrent fever, vomiting, loss of consciousness, altered sensorium, swallowing difficulty and deviation of head and
'Dr. S Kalyan Kunchapudi, MBBS, DNB (Paediatrics), ${ }^{2}$ Dr. Praveen Kumar, MBBS, DNB, Fellowship in Paediatric Neurology, Consultant Neurologist, ${ }^{3}$ Dr. R K Sabharwal MD, DM, Senior Consultant and Head, Department of Paediatric Neurology, Sir Ganga Ram Hospital, New Delhi.

Address for correspondence:

Dr. Praveen Kumar

E-mail: drpraveensingh31@yahoo.com

\section{How to cite}

Kunchapudi SK, Kumar Praveen, Sabharwal RK. Opsoclonus Myoclonus Ataxia Syndrome. J Nepal Paediatr Soc 2015;35(1):70-72.

doi: http://dx.doi.org/10.3126/jnps.v35i1.11201

This work is licensed under a Creative Commons Attribution 3.0 License.

\section{(c) (i)}

neck, eyes with limb movements. He was born by normal vaginal delivery at term with no complications. Development was appropriate for age.

On examination he was alert, conscious and oriented. No pallor, icterus cyanosis, lymphadenopathy, oedema was found. No evidence of any neurocutaneous markers was seen. His weight for age was $90^{\text {th }}$ centile and height for age was $75^{\text {th }}$ centile as per $\mathrm{CDC}$ growth charts. His vitals were normal. There were continuous coarse tremors of head and limbs. Ataxias as well as dysmetria were present on both sides. Muscle tone, power and reflexes were normal. There were no signs of meningitis. His cardiovascular, abdominal, respiratory 
system examination was normal. Subsequently on the third day of admission he became irritable and had sleep disturbances. This time child was found to have opsoclonus, as conjugate eye movements. Diagnostic possibility of Opsoclonus myoclonus ataxia (OMA) was kept and was investigated thoroughly.

On investigations, his haemoglobin was 12.8 $\mathrm{gm} / \mathrm{dl}$, total leucocyte count - $16000 / \mu \mathrm{l}$, platelet count 4.53 lacs $/ \mu \mathrm{l}$. ESR was $5 \mathrm{~mm} / 1^{\text {st }}$ hour. Blood urea nitrogen $-12 \mathrm{mg} / \mathrm{dl}$, creatinine $-0.25 \mathrm{mg} / \mathrm{dl}$, SGOT$20 \mathrm{IU} / \mathrm{L}, \mathrm{SGPT}-16 \mathrm{IU} / \mathrm{L}, \mathrm{S}$. lactate and ammonia were within normal limits. CSF analysis revealed cell count 55 with $88 \%$ lymphocytes with glucose of $53 \mathrm{mg} /$ $\mathrm{dl}$ and protein of $28.9 \mathrm{mg} / \mathrm{dl}$. CSF culture was sterile and CSF PCR for Enteroviruses and Herpes virus was negative. Serology for mycoplasma was negative. MRI Brain was normal and ultrasound abdomen, done for any abdominal mass or adrenal mass, was normal. CECT chest revealed mild right para and pre vertebral soft tissue thickening at D4-D6 vertebrae. MRI Spine revealed right para-vertebral soft tissue thickening at D4-D6 region with normal underlying vertebrae. MRI brain was normal. Urine 24-hour VMA levels and urine spot catecholamines were within normal limits. MIBG scan (iodine-131-meta-iodobenzylguanidine) was not done due to financial reasons.

He was started on Methylprednisolone at 30mg/ $\mathrm{kg} /$ day for three days and then shifted to injection ACTH at dose of $40 \mathrm{IU} / \mathrm{m}^{2} /$ day, as symptoms persisted. With ACTH, after two doses, child improved, irritability settled and intensity of myoclonus also decreased. He was discharged after seven days in better condition on ACTH. After two months of follow up, the intensity of myoclonus further decreased and child started to walk unaided.

\section{Discussion}

OMA is most commonly associated with neural crest derived tumours, (like neuroblastoma (up to $40 \%$ ), ganglioneuroblastoma, ganglioneuroma), as a para- neoplastic presentation ${ }^{3}$. The pathogenesis was thought to be immune mediated, with a cross-reactive autoimmunity between neuroblastoma cells and the central nervous system ${ }^{4}$. Several serum autoantibodies against neurons and cerebellar Purkinje cells have been identified in patients with OMA with unknown specificity ${ }^{5}$. However OMA is also attributed to be due to other etiologies like Para-infectious (Coxsackie B, EBV, Rubella, Herpes, Mumps, St. Louis encephalitis, Salmonella, Hemophilus influenzae), Toxic, Metabolic (multiple carboxylase deficiency, ketamine, tricyclic anti-depressants, mercury salts, phenytoin) ${ }^{6}$.
This condition is one of the important differentials for acute post infectious cerebellar ataxia and is mainly distinguished by presence of irritability and opsoclonus in OMA, which are rare in the former. In contrast to cerebellar ataxia, the outcome is far disabling and requires more extensive work up as well as long term immunomodulation therapy ${ }^{3}$.

After diagnosis, a thorough investigation for an occult neuroblastoma need to be done, like CT imaging of thorax, abdomen, functional imaging using PET or MIBG scintigraphy? ${ }^{7}$. Urine should be tested for catecholamines apart from strict monitoring of blood pressure. Testing for serum auto antibodies have limited yield. Failures to find tumours do not rule out paraneoplastic OMA as these tumours are known to regress spontaneously in some. If initial screening is negative periodic follow up for at least two years and repeat investigations every 3-6 months and if no neoplasm is detected till two years of follow up and no obvious etiology is detected then it is labelled as idiopathic. CSF evaluation is required especially in children who do not have an identifiable neuroblastoma for infectious and para-infectious etiology. Mild elevation of protein and pleocytosis can be seen in both infectious and paraneoplastic etiology.

Mainstay of treatment lies on immunomodulation ${ }^{3}$. Neuroblastoma, if present, needs tumour resection with or without chemotherapy. Therapeutic options for immunomodulation are: Adrenocorticotrophic hormone (ACTH), Methyl prednisolone pulses followed by oral steroids, Intravenous immunoglobulin. Reports have shown that $\mathrm{ACTH}\left(40 \mathrm{IU} / \mathrm{m}^{2} /\right.$ day $)$ has faster action than methyl prednisolone ${ }^{3}$. Combination therapy can be used for refractory cases and other refractory or relapsers may be benefited by Rituximab, Plasmapheresis, Azathioprine, Cyclophosphamide and Mycophenolate mofetil ${ }^{8}$.

Opsoclonus myoclonus have substantial developmental sequelae includes cognitive, motor, speech and language deficits, and behavioural sequelae ${ }^{9}$. About $61 \%$ have chronic relapsing course, half have intellectual deficit and more than half have residual motor and speech deficits ${ }^{10}$.

\section{Conclusion}

It is important to consider Opsoclonus myoclonus ataxia syndrome whenever a child presents with an acute onset ataxia with irritability, facilitating early evaluation and initiation of treatment. Opsoclonus may present later emphasising need for close observation. 


\section{References}

1. Kinsbourne M. Myoclonic encephalopathy of infants. J Neurol Neurosurg Psychiatr. 1962;25(3):271-276.

2. Matthay KK, Blaes F, Hero B, et al. Opsoclonus myoclonus syndrome in neuroblastoma a report from a workshop on the dancing eyes syndrome at the Advances in Neuroblastoma meeting in Genoa, Italy, 2004. Cancer Lett 2005;228(1-2):275-282.

3. Tate ED, Allison TJ, Pranzatelli MR, et al. Neuroepidemiologic trends in 105 US cases of pediatric opsoclonus-myoclonus syndrome. J Pediatr Oncol Nurs 2005;22(1):8-19.

4. Blaes F, Pike MG, Lang B. Autoantibodies in childhood opsoclonus-myoclonus syndrome. J Neuroimmunol 2008;201-202:221-226.

5. Korfei M, Fühlhuber $V$, Schmidt $T$, et al. Functional characterisation of autoantibodies from patients with pediatric opsoclonus-myoclonus-syndrome. J Neuroimmunol. 2005;170(1-2):150-157.
6. Michael R. Pranzatelli. The Neurobiology of the Opsoclonus-Myoclonus Syndrome. Clinical Neuropharmacology, Vol. 15, No. 3, pp. 186-228. 1992 Raven Press, Ltd., New York.

7. Pang K, de Sousa C, Lang B, et al. A prospective study of the presentation and management of dancing eye syndrome/opsoclonus-myoclonus syndrome in the United Kingdom. Eur J Paediatr Neurol 2010;14(2):156-161.

8. Pranzatelli MR, Tate ED, Kinsbourne $M$, et al. Forty-one year follow-up of childhood-onset opsoclonus-myoclonus-ataxia: Cerebellar atrophy, multiphasic relapses, and response to IVIg. Mov Disord 2002;17(6):1387-1390.

9. Mitchell WG, Davalos-Gonzalez Y, Brumm VL, et al Opsoclonus-ataxia caused by childhood neuroblastoma: developmental and neurologic sequelae. Pediatrics 2002;110(4):853-854.

10. Brunklaus A, Pohl A, Zuberi S et al. Outcome and Prognostic Features in Opsoclonus-Myoclonus Syndrome From Infancy to Adult Life. Pediatrics 2011;128(2):e388-e394. 